\title{
The Training of Coaching Skills: an implementation study
}

\section{SIMON VEENMAN}

Department of Educational Sciences, University of Nijmegen, P.O. Box 9104, 6500 HE Nijmegen, The Netherlands

SUMMARY In this study, the implementation effects of a programme for the training of coaching skills with Dutch school counsellors are described. These school counsellors are expected to provide help and support to primary school teachers. Coaching is a form of in-class support intended to provide teachers with feedback on their own functioning and thereby stimulate self-reflection and self-analysis in order to improve instructional effectiveness. To assist school counsellors in their attempts to coach teachers, a training programme was designed: 'The school counsellor as coach.' $A$ quasi-experimental, treatment-control group investigation was then set up to test the effects of this programme. Based on the pre-and post-training ratings of coaching conferences, a significant treatment effect was found for the coaching skills concerned with the development of autonomy (empowerment), feedback, and purposefulness. The pre- and posttraining ratings from coached teachers showed no significant treatment effects. This was because the teachers were not accustomed to in-class assistance and thus rated the coaching skills of the school counsellors quite favourably even at pre-test.

\section{Introduction}

In the Dutch educational support system, clinical supervision or coaching is not a common practice. About 60 local or regional school guidance centres (Schoolbegeleidingsdiensten) provide support to primary schools (including nursery schools) and help solve problems. The work of the school guidance centres includes advising, guidance, development activities, evaluation, and the provision of information. The guidance, support, and advice is mostly directed at the school as a whole or at specific groups of teachers. The school guidance centres arose out of the needs of the schools themselves, with the support provided by these centres considered a major instrument in the promotion and maintenance of the quality of education in The Netherlands. Houtveen (1990) found the guidance provided by school counsellors to consist mainly of conversations and the provision of information to the school staff as a whole. This policy of disseminating information for innovation only at the level of the school proved to be largely ineffective. In-classroom support was only 'seldom' or 'sometimes' provided. When such in-class support was provided, however, it 
was found to correlate significantly higher than school-wide support with 'innovative teacher behaviours'.

Based on the recognition that in-class support by school counsellors can improve the instructional effectiveness of teachers, the Protestant Educational Advisory Centre (CPS) and Department of Educational Sciences at the University of Nijmegen undertook the development of a coaching programme for school counsellors. This decision was also motivated by the positive findings of research with regard to the staff development program 'Dealing with multigrade classes' (Veenman et al., 1989). In this research, teachers who were both trained and coached improved more on instructional effectiveness than teachers who were only trained (Roelofs et al., 1994). The effects of coaching nevertheless proved to be less than expected, and inspection of the coaching processes showed the school counsellors to give different interpretations to the practice of coaching. The school counsellors also reported feeling less than fully prepared for the task and expressed the desire for more formal training with concrete examples of the various coaching skills. In the present study, the implementation effects of such a programme are described.

\section{Coaching}

In a recently published report on the future of the teaching profession to the Dutch Minister of Education, it was noted that teachers need greater feedback with regard to their professional practice. The isolation of teachers in their classrooms was considered to have negative effects on the development of shared professional norms, collegiality, instructional effectiveness, and self-renewal. The committee pleaded for the development of more professional skills including self-reflection, self-appraisal, and self-direction (Commissie Toekomst Leraarschap, 1993).

Coaching can clearly help teachers to improve their instructional effectiveness by providing them with feedback on their functioning and stimulating them to become more reflective. Coaching is also closely related to the concept of clinical supervision, which nevertheless has a much longer educational tradition. Clinical supervision is defined by Sergiovanni \& Starrat (1983) as: 'An in-class support system designed to deliver ... assistance directly to the teacher ... to bring about changes in classroom operation and teacher behaviour' (p. 299). The term 'clinical', according to Goldhammer (1969), is intended to convey the image of a face-to-face relation between supervisors and teachers as opposed to supervision from a distance. Clinical supervision is also meant to imply the close-up supervision of professional practice; what the teacher actually does in the classroom stands central. Observational data collected in the classroom are the grounds for subsequent analyses, and the categories for analysis are developed on the basis of such observation (and not before). The same meaning of 'clinical' is found in the work of Cogan (1973), where the term implies the direct observation, analysis, and treatment of actual cases and concrete problems with a focus on the in-class behaviour of teachers and students. 
The term 'supervision' implies inspection or evaluation and often evokes negative reactions among teachers. The term 'coaching' is therefore being used more and more frequently. In this light, certain educators emphasise the parallels between coaching in educational settings and coaching in sport settings-for example, Joyce \& Showers (1982). For Costa \& Garmston (1994), 'coaching' is a form of conveyance or a stagecoach; to coach means to convey teachers from where they are to where they want to be, and is a non-judgemental process.

In the Dutch training manual for school counsellors, 'coaching' is defined as a form of in-class support to help teachers enhance and renew their craftsmanship on the basis of systematic reflection on their professional practice (Veenman et al., 1995). The coaching is directed at strengthening the instructional competence of teachers. This implies professional growth and autonomy, or what is called empowerment. Teachers are assisted by coaches, and this assistance is based on pre-conference, observation, and post-conference. These phases in the coaching process were drawn from the various models of clinical supervision and coaching available in the literature, and those models that contributed to the development of the Dutch training manual, The School Counsellor as Coach, will therefore be reviewed below.

\section{Some Approaches to the Clinical Supervision and Coaching of Teachers}

Approaches to the clinical supervision of teachers have their roots in the work of Cogan and Goldhammer. During the 1960s, these authors developed a training programme at Harvard University for the induction of new teachers into the profession. This programme was based on the techniques of classroom observation, concrete data collection and the holding of supervisory conferences. Their approach to supervision was a reaction to the more traditional forms of supervision that relied heavily on inspection. These included the monitoring and overseeing of the curriculum and its instruction along with the evaluation of teacher performance and student achievement. The models proposed by Goldhammer and Cogan, in contrast, portray clinical supervision as the provision of support for teachers, with the increase of professional responsibility, autonomous functioning, and the capacity for self-analysis and self-direction as the goal. In their view, clinical supervision is intended to help teachers improve by recognising their existing strengths and building on these. Such recognition, however, requires the supervisor to regard the teacher as professionally competent (Pajak, 1993).

According to Goldhammer (1969), clinical supervision ought to enhance the teacher's ability for self-supervision and the supervision of their colleagues. The basic model of clinical supervision described by Goldhammer consists of five stages: (1) pre-observation conference, (2) observation, (3) analysis and strategy, (4) supervision conference, and (5) post-conference analysis. These stages constitute the 'sequence of supervision', and a number of such sequences together is called the 'cycle of supervision.' 
The first stage of clinical supervision requires the establishment of a relaxed relationship between the teacher and the supervisor. Understanding the teacher's frame of reference is necessary. The supervisor's task is also to understand and refine the teacher's plan for the lesson that will be observed and in such a way identify the specific problems that the teacher appears to be grappling with. The pre-observation conference is also a time to clarify the reasons for supervision in the classroom and reach an agreement on how the supervision should operate.

During the second stage of clinical supervision or observation, the supervisor observes what is happening in the classroom in order to provide the teacher with an objective and comprehensive description of the events. Such descriptive data are provided to help the teacher become more aware of his or her own behaviour and evaluate the reality of their own perceptions and judgements.

The third stage of clinical supervision has two purposes. The first goal is to make sense of the observational data. The data must be made intelligible and manageable. The second goal is to plan the supervision conference that is to follow. What issues should be treated? Which data should be cited? Which goals should be developed? How should we begin? And how should we end?

The fourth stage of clinical supervision, or the post-observation conference, is the most essential stage in the 'sequence of supervision.' This stage is intended to give the teacher the opportunity to deal with the supervisor's analysis of the teaching process and mention any problems with the analysis in order to make explicit decisions with regard to future teaching. The feedback provided to the teachers should be relative to their performance and strictly for the improvement of their teaching and not for evaluation. The post-observation conference is also a time for possibly redefining the supervisory contract and offering didactic assistance to the teachers.

In the fifth or final stage of clinical supervision, the post-conference analysis, the supervisor critically examines his or her own supervisory effectiveness. This can be done alone or in conjunction with other supervisors.

The model of clinical supervision proposed by Cogan (1973) is intended to produce professionally responsible teachers who are thus self-directing, capable of objectively analysing their own performance, and open to the receipt of assistance (Pajak, 1993). Clinical supervision is concerned with the improvement of the instructional skills of individual teachers, and Cogan distinguishes eight phases in the clinical supervision cycle: (1) establishing the teacher/supervisor relationship: the introduction of the teacher to the philosophy, objectives, processes and techniques involved in clinical supervision and the induction of the teacher into the role of colleague; (2) planning with the teacher: the teacher and supervisor co-operatively plan the best lesson they can; (3) planning the structure of the observation, with the supervisor asking which aspects of the lesson the teacher might want to know more about; (4) observing the instruction with data collected on the teacher's behaviour, the students' behaviour, and any other events that may occur in the classroom; (5) analysing the teaching/learning processes on the basis of the observational data in order to develop hypotheses 
about the possible relations between the teacher's behaviour and student learning; (6) planning the structure of the conference-the supervisor makes a tentative plan; (7) the conference: the supervisor and the teacher confer, search for meaning in the data, and select one or more strategies for the improvement of instruction; and (8) renewed planning, which is a return to phase two, followed by a repetition of the clinical cycle: another lesson is collaboratively planned and another observation is scheduled. Cogan (1973) argues that all teachers need systematic, sustained, expert assistance in order to achieve their potential. Assistance in the form of 'in-class support' will be particularly needed when they experiment with new methods, and clinical supervision can provide this assistance.

The work of Goldhammer has been updated by Anderson \& Krajewski. In the second and third edition of Goldhammer's work, however, the original five-stage cycle of supervision has been maintained (Goldhammer et al., 1980, 1993).

In the 1980s, the original models of clinical supervision were supplemented by more technical/didactic models. Examples are the models described by Joyce \& Showers (1980, 1988) and Hunter \& Russell (1990). In these models, classroom observation and conferencing are used to coach teachers in the proper enactment of teaching behaviours and strategies that have been shown to be particularly 'effective' by researchers on instruction and learning (Pajak, 1993).

In reviewing the research on the ability of teachers to acquire new teaching skills and transfer these skills to the classroom, Joyce \& Showers $(1980,1988)$ identified five major components for effective training: (1) presentation of the theory or clear description of the skill/strategy; (2) modelling or demonstration of the relevant skills and strategies; (3) practice in simulated and real classroom settings; (4) provision of structured and open-ended feedback on performance; and (5) 'coaching for application (hands-on, in-classroom assistance with the transfer of the skills and strategies to the classroom)'. In the work of Joyce $\&$ Showers, coaching is attached to training, ongoing, experimental in nature, and separate from supervision and evaluation. Joyce \& Showers (1982) also argue for the development of a 'coaching environment' where all of the personnel see themselves as one another's coaches. In this light, the coaching process serves five major functions: (1) the provision of companionship for strong psychological support; (2) the provision of technical feedback; (3) analysis of the appropriateness of the use of the target skills and the possible consequences of their applications; (4) adaptation of newly acquired skills to the students in the classroom; and (5) facilitation of continued practice.

The coaching and supervision model advocated by Hunter \& Russell (1990) is based on the view that knowledge and application of cause-effect relations between the behaviour of teachers and student learning can increase the probability of teacher success. Coaching and supervision thus have the power to foster effective teaching, which involves three essential domains of decision: content, learning behaviour, and teaching behaviour. Staff development programmes should supply research-based declarative knowledge (psycho- 
logical and educational propositions) and assist in the translation of this knowledge into procedural as well as conditional knowledge. Coaching and supervision can then help in the further translation of this knowledge gained from staff development into skilled professional practice. A 'script tape' (a running anecdotal record of what was actually said or done) can provide a clear source of data for the subsequent instructional conference. The coaching and supervisory conferences have three functions: the promotion of a teacher's professional growth in terms of effective instruction, the provision of objective evidence with regard to instructional behaviours, and the encouragement of continued professional growth. A noteworthy feature of Hunter \& Russell's approach to coaching and supervision is the elimination of the pre-conference. Given our knowledge of the cause-effect relations between teaching and learning, Hunter (1986) argues that it is time to discard the time-consuming pre-observation conference. Teachers should know at the beginning of the academic year that the purpose of observation is to promote instructional effectiveness. The necessary trust and support for successful staff development depends primarily on what happens in the post-observation conference. In addition, the pre-observation conference is likely to bias the teacher and the observer with regard to the lesson. Finally, Hunter believes that the time required for the pre-conference reduces the time available for observation and additional conferences by at least one-third. In some specific instances, Hunter nevertheless believes that a planning conference may be beneficial. When the observer and teacher collaborate in the design of a lesson, which the teacher subsequently teaches, the responsibility for a successful learning outcome is jointly shared and may be welcome under certain circumstances.

Costa \& Garmston (1994) advocate a model of supervision called 'cognitive coaching'. In their developmental/reflective approach to coaching, teaching is considered a professional act and the task of the coach is to help teachers become more resourceful, informed, and skilled professionals. While the traditional model of clinical supervision focuses on overt teaching behaviour, cognitive coaches attend to the internal thought processes associated with teaching. Changing these inner thought processes is considered a prerequisite for the improvement of the overt behaviour that can, in turn, enhance student learning. Cognitive coaching is also linked to teacher reflection and organised around three major goals: (1) the establishment and maintenance of trust; (2) the facilitation of mutual learning; and (3) the enhancement of growth towards autonomy and self-actualisation. The cognitive-coaching cycle consists of three steps: (1) the planning conference, (2) the observation, and (3) the reflecting conference. In the planning conference, the coach's attention is centred on the teacher's goals, the lesson is mentally rehearsed and the parameters for the reflecting conference are established. During classroom observation, the coach collects data on the behaviours and learning as discussed in the planning conference and requested by the teacher. In the reflecting conference, the coach invites the teacher to make comparisons between what was desired and what was realised. The coach facilitates the teacher's analysis of the lesson goals by 
sharing data and posing reflective questions. The aim is to support the teacher's ability to identify the causal relations between teaching behaviours and student learning.

Each of the models described above for the clinical supervision or coaching of teaching contains a number of concretely defined skills. In the design of the training manual for Dutch school counsellors, a selection was made from these skills. This rather eclectic synthesis was also inspired by the in-service programme, Another Set of Eyes, from the Association for Supervision and Curriculum Development (1988). Three basic stages of coaching were selected for use: pre-conference, observation and post-conference. The specific content of the training will be described in a later section of this article. In the following section, the actual effects of clinical supervision or coaching will be considered.

\section{The Effects of Clinical Supervision or Coaching}

Examination of the results of 11 clinical supervision studies focused on the attitudes towards supervision. Pavan (1985) showed principals and teachers to be more positive towards clinical supervision (i.e. the Goldhammer-Cogan model) than towards traditional forms of supervision. By examining the structures and activities common to six case-studies of clinical supervision for teachers, Nolan et al. (1993) identified five conditions that appear to maximise the effects of clinical supervision: (1) the development of a collegial relationship in which the teacher feels safe and supported; (2) teacher control over the products of supervision; (3) continuity in the supervisory process over time; (4) specific, descriptive records of actual teaching and learning events; and (5) reflection by both the teacher and the supervisor as the heart of the post-conferencing.

To date, no study - either quantitative or qualitative--has demonstrated the impact of clinical supervision on student achievement itself (Nolan et al., 1993). The causal chain from supervisory behaviour to teacher behaviour to student behaviour is a long one with many intervening variables. Nolan et al. (1993) argue that carefully controlled studies with variables defined before intervention simply violate the principles of clinical supervision. This is because the process of clinical supervision should be driven by the concerns of teachers. Pavan (1985) identified only four published reports on the relation between clinical supervision and student achievement. All of these studies were doctoral dissertations and, according to Pavan, the quality ranged from highly questionable to excellent. Three of the four studies relied on the Hunter model of clinical supervision; one study used the Goldhammer-Cogan model. In only one of the four studies (using the Hunter model) was student achievement found to be statistically higher for teachers who were clinically supervised. After a reanalysis of the data, Pavan concluded that teacher and principal effects and gross differences in supervisory time had more influence on student achievement than clinical supervision. Thus, whether a relation can be established between clinical supervision and student achievement has yet to be determined (Pavan, 1985). 
Sparks \& Bruder (1987) examined whether coaching practices might improve the collegiality in schools and foster greater experimentation with new teaching practices. The results showed coaching to produce greater collegiality and experimentation with different teaching techniques. Showers (1982) and Baker (1983) examined the effects of coaching on (1) the ability of teachers to incorporate newly acquired strategies into their instructional repertoire, and (2) on student achievement. The results of these studies showed teachers who underwent the training programme with coaching to have a greater degree of skill retention-in both the short and long run-than teachers who underwent the same training programme without coaching. Coaching appeared to be a necessary condition for the transfer of training when the object of the staff development programme was to improve teaching skills. No coaching effects were found for student achievement on essay tests. Clear transfer effects as a result of coaching were also found in a meta-analysis by Bennett (1987). The results of this study showed coaching in the classroom to produce transfer effect sizes 1.3 standard deviations higher than no coaching.

The efficacy of coaching in the facilitation of transfer to classroom practice was also examined in a Dutch study by Roelofs (1993) and Roelofs et al. (1994). Teachers who received coaching as an additional component in a staff development programme directed at teachers in multigrade classes performed better than uncoached teachers on two of the 10 measures concerned with the teachers' instructional and classroom management skills. Coached teachers organised their instruction more effectively and dealt more efficiently with classroom disturbances. The students of coached teachers also showed greater levels of time on-task. No direct relation was found between coaching and student achievement, however (Veenman \& Raemaekers, 1995).

As already noted, school counsellors in our studies varied in their ability to coach effectively. Although a number of coaching scenarios for coaching were provided, the school counsellors nevertheless expressed a desire for more formal training with well-defined coaching skills. In the light of the positive effects of coaching with respect to the transfer of training, changes in teacher thinking and behaviour, greater teaching awareness, and increased collegiality, it was decided to design a coaching programme for school counsellors.

\section{Research Questions}

In the present study, the effects of a training programme on the coaching skills of Dutch school counsellors were examined. The major research questions were: (1) Do the school counsellors who participated in the training programme implement the target coaching skills? (2) Do the teachers coached by the school counsellors who participated in the training programme perceive a change in the coaching skills of the school counsellors? 


\section{Method and Instrumentation}

\section{Design}

Two different forms of evaluation were undertaken in the present study. First, the coaching of trained versus untrained school counsellors was rated by expert judges. Second, the coaching of the trained and untrained school counsellors was rated by the coached teachers. Both evaluations were concerned with the degree of implementation of the desired coaching skills by the school counsellors. The coached teachers were also asked to estimate the effect of coaching by the school counsellors on their instructional practice.

Both of the evaluation studies were set up as a field quasi-experimental pre-test-post-test design. In the first evaluation, the experimental group consisted of 18 trained school counsellors and the control group consisted of 10 untrained school counsellors. In the second evaluation, the experimental group consisted of the 18 teachers coached by the trained school counsellors, and the control group consisted of eight teachers coached by the untrained school counsellors.

\section{Subjects}

A letter of invitation for participation in a training programme devoted to the coaching of teachers was sent to 60 school guidance centres in The Netherlands and to one school guidance centre in Belgium (Flanders). Only those school counsellors with little or no coaching experience were invited to participate in the programme. The response was greater than expected $(n=39)$ and two groups were therefore formed. Group one received training in September 1993 and constituted the experimental group; group two received training in January 1994 and constituted the control group. From the 39 school counsellors, 25 were randomly assigned to the experimental group and 14 randomly assigned to the control group. Both the experimental and control groups consisted of school counsellors interested in coaching and were thus initially comparable. In the end, 18 school counsellors participated in the experimental group, and 10 school counsellors in the control group. The remaining school counsellors were unable to find the time for participation or could not find teachers interested in coaching.

The average amount of experience for the school counsellors was 8 years. The average age of the school counsellors was 35 years. Of the total group, $67 \%$ were women and $33 \%$ were men. The average amount of experience for the teachers coached by the school counsellors was 12 years. The average age of the teachers was 36 years. Of the total group of teachers, $70 \%$ were women and $30 \%$ were men.

After completion of a coaching conference with the school counsellors, the coached teachers were asked to rate the performance of the school counsellors and estimate the effect of the coaching conference on their instructional behaviour. Of the 18 teachers coached by the trained school counsellors, all of 
the teachers returned their questionnaire (response rate of $100 \%$ ). Of the 10 teachers coached by the untrained school counsellors, eight teachers returned their questionnaires (response rate of $80 \%$ ).

\section{Scale for Coaching Skills}

All of the coaching conferences were taped by the school counsellors. These tapes were coded by two expert raters using the Scale for Coaching Skills (SCS). This scale was also used by the coached teachers to rate the skills of the school counsellors and estimate the effect of the coaching conference on their own teaching behaviour. The SCS ranges from a score of 1 for no application of the skill to a score of 5 for clear application of the skill. The original version of the SCS contained 32 variables. A number of variables were derived from the 'Snyder-Pavan Clinical Supervision Practices Questionnaire' (Pavan, 1991, 1993). The inter-rater reliability checks using Cohen's Kappa (1960) were found to range between 0.63 and 1.00 (median 0.85 ). Four variables were then removed from the scale: two variables because of their low inter-rater reliability and two variables because of their low degree of variability. The final version of the SCS thus contained 28 variables.

Based on the results of a principle components analysis on the judges' SCS scores, four factors (or subscales) were formed: (1) 'developing autonomy' (12 items, alpha $=0.94)$; (2) 'feedback' (5 items, alpha $=0.84)$; (3) 'purposefulness' (7 items, alpha $=0.87$ ); and (4) 'trust building' ( 4 items, alpha $=0.61$ ). These four factors accounted for $72 \%$ of the rating variance. The scores from the coached teachers produced a fifth factor: 'perceived effects of the coaching conference on instructional skills' (12 items, alpha $=0.88)$.

\section{The Training Programme}

The training manual, The School Counsellor as Coach, consisted of five sections. In section one, the contribution of coaching to the improvement of instructional effectiveness is discussed in the context of the school as a learning organisation. Information is provided on the functions of coaching and the skills needed by both coaches and teachers. Coaching is shown to be related to the improvement of individual teacher instruction. School counsellors are instructed to support teachers in becoming more resourceful and skilful. They are encouraged to invite teachers to reflect on the possible discrepancies between desired and actual teaching behaviour and the possible relations between teacher behaviour and student achievement.

In section two, four different forms of coaching are described: counselling, mentoring, tutoring and confronting. The training in this study was directed at tutoring, which involves increased competence, movement to expert status, and commitment to continual learning (cf. Kinlaw, 1989). Tutoring is also described as being supplemental to the teacher's own willingness and initiative for self-im- 
provement. In this same section, the three stages in the coaching process are also described: pre-conference, observation and post-conference.

In section three, the coaching skills for the pre-conference are discussed. Attention is devoted to skills such as trust-building, problem definition, problem-solving, planning alternatives, and action plans for improvement.

In section four, the observation of teaching is discussed. 'Script taping' is considered in detail. This involves making a written record of what is said and done during an observed class session.

In section five, the final section of the training manual, post-conference coaching skills are discussed. These include probing for teachers' feelings about the lesson, evaluating the outcomes of the action plans, discussing the observational data (reflecting and providing feedback), developing new alternatives, and refining action plans. The school counsellors are advised to invite the teacher to give feedback and suggest any refinements that could make for a more productive relationship.

The coaching skills for the pre-conference and the post-conference are structured around the three stages proposed by Kinlaw (1989): (1) involvement (clarifying the purpose of the conference, developing comfort and trust); (2) development (communicating information that leads to problem definition and insight into the problem); and (3) resolution (achieving closure and planning the next steps). The contents of the training manual formed the basis for a 1 day workshop. Prior to this workshop, the manual was sent to the school counsellors in the treatment group with the request to study at least the sections on pre-conference, observation and post-conference. During the workshop; the school counsellors were trained in the skills relevant to the pre-conference, observation and post-conference. During the application exercises, the participants formed groups of three and alternated being the coach, teacher, or observer. After each exercise, the school counsellors then designed action plans for their own coaching practice. Exercises in 'script taping' were based on video fragments of lessons. The school counsellors rated the training manual and workshop quite favourably and indicated that they planned to apply the newly learned coaching skills in the near future.

\section{Data Collection}

Prior to training, the school counsellors conducted a coaching conference with one or two primary school teachers. The school counsellors were asked to conduct this conference in a manner similar to the conferences they usually performed. This pre-test was conducted between May and August 1993. As already noted, the workshop took place in September 1993. After the workshop, the school counsellors again conducted a coaching conference with the same teachers. Most of the school counsellors were not able to conduct the post-test before December 1993. The deadline for the post-test was mid-February 1994, and a maximum of three reminders was sent.

Of the trained school counsellors, $36 \%$ conducted a coaching conference 
with two teachers and $64 \%$ with one teacher. These figures were $30 \%$ and $70 \%$ for the untrained school counsellors. The trained school counsellors were expected to conduct the complete coaching cycle of pre-conference, observation, and post-conference in the post-test. Of the trained school counsellors, however, $78 \%$ conducted the entire coaching cycle. Of the untrained school counsellors, $20 \%$ conducted an entire coaching cycle. Inspection of the pre- and post-test coaching conferences showed almost all of the school counsellors to conduct a post-conference; that is, the school counsellors conducted a coaching conference using observational data on actual teaching behaviours.

All of the coaching conferences were audio-taped by the school counsellors, and the tapes were sent to the raters for coding. After each coaching conference, the coached teachers also rated the coaching skills of the school counsellors. The school counsellors did not have access to the teacher ratings.

For those school counsellors who conducted coaching conferences with two teachers, the ratings were averaged to form a single score. The ratings of the preand post-test coaching conferences were also averaged to produce a mean score for each school counsellor. In testing for differences between the trained and untrained school counsellors on the one hand, and between the pre- and post-tests, on the other hand, a significance level of $5 \%$ was used (one-tailed). The school counsellor was the unit of analysis. For a more detailed description of the design, instrumentation and data collection, see de Jonghe $\&$ van Wezel (1994).

\section{Results}

Comparison of the trained group with the untrained group for initial differences prior to training revealed no significant differences. A one-tailed $t$-test for paired samples was used to examine the differences between the pre- and post-test data for the trained and untrained groups of school counsellors. Independent onetailed $t$-tests were used to examine the gain-scores (post-test scores minus pre-test scores) for the trained versus the untrained groups. A summary of the Scale for Coaching Skills (SCS) scores from the expert raters for the trained and untrained school counsellors at pre- and post-test is presented in Table I.

The data displayed in Table I show training to have a marked effect on the coaching skills of school counsellors. Significant differences between pre- and post-test for the trained school counsellors were found on the total SCS and three subscales: 'developing autonomy,' 'purposefulness,' and 'trust building'. Significant differences were found for the subscale 'feedback' for the post-conference but not for total feedback (pre- and post-conference taken together). No significant pre-versus post-test differences were found for the untrained school counsellors. Significant differences between trained and untrained school counsellors were found for the total SCS and three subscales: 'developing autonomy', 'purposefulness', and 'feedback' (for the post-conference).

The trained school counsellors were expected to conduct two coaching conferences during the post-test: a pre-conference and a post-conference. The 
TABLE I. Mean SCS scores of expert raters and results of $t$-tests for differences between preand post-test data and differences between gain scores for trained and untrained school counsellors

\begin{tabular}{|c|c|c|c|c|c|c|c|}
\hline \multirow{2}{*}{$\begin{array}{l}\text { Scale for Coaching } \\
\text { Skills (SCS) }\end{array}$} & \multicolumn{2}{|c|}{$\begin{array}{l}\text { Trained group } \\
\quad(n=18)\end{array}$} & \multicolumn{2}{|c|}{$\begin{array}{l}\text { Untrained group } \\
\qquad(n=10)\end{array}$} & \multicolumn{2}{|c|}{ Pre-post gain } & \multirow[b]{2}{*}{$t$} \\
\hline & Pre & Post & Pre & Post & $\begin{array}{l}\text { Trained } \\
\text { group }\end{array}$ & $\begin{array}{l}\text { Untrained } \\
\text { group }\end{array}$ & \\
\hline SCS: total & 2.29 & $3.47 \dagger$ & 2.15 & 2.14 & 1.18 & -0.01 & $8.01 t$ \\
\hline Developing autonomy & 1.39 & $3.13 t$ & 1.32 & 1.32 & 1.75 & -0.00 & $7.18 t$ \\
\hline $\begin{array}{l}\text { Feedback: total } \\
\text { Feedback: }\end{array}$ & 2.99 & 2.52 & 2.78 & 2.58 & -0.47 & -0.20 & -0.45 \\
\hline postconference* & 3.34 & $4.53 \dagger$ & 3.23 & 3.03 & 1.19 & -0.19 & $2.35^{\star \star}$ \\
\hline Purposefulness & 2.57 & $4.12 \dagger$ & 2.28 & 2.12 & 1.54 & -0.16 & $7.88 \dagger$ \\
\hline Trust building & 3.60 & $4.52 \dagger$ & 3.61 & 4.09 & 0.92 & 0.48 & $0.10^{\circ}$ \\
\hline
\end{tabular}

Note: ${ }^{\star}$ Untrained group $n=9 ;{ }^{\star \star} p<0.05 ; \dagger p<0.01$.

provision of feedback was considered an essential ingredient in the post-conference, moreover. That is, the teacher should be given information about his or her actual teaching performance based on actual observational data. For this reason, an independent examination of the scores for the post-conference was undertaken. The outcome of this analysis showed the trained school counsellors to make significantly better use of feedback than the untrained school counsellors.

In order to examine the possible influence of a number of background characteristics, supplementary analyses were conducted with the following control variables: (1) the number of years working as a school counsellor, (2) prior knowledge of the coaching process, and (3) prior experience with coaching. No significant effects were found for these control variables.

A summary of the SCS scores from the coached teachers for the trained and untrained school counsellors at pre- and post-test is presented in Table II. The total score for the SCS was based on the mean scores for the initial four subscales; the total SCS score and the scores for the four subscales were thus comparable to the scores from the expert raters. The fifth subscale was specially constructed for the coached teachers in order to examine their views about the effects of the coaching conferences on their instructional practices.

The results in Table II show the trained school counsellors to score significantly higher on the subscale 'developing autonomy' after completion of the training. No significant differences were found for the trained school counsellors on the remaining four subscales. In addition, no significant differences were found between the trained and untrained school counsellors. It 
TABLE II. Mean SCS scores of coached teachers and results of $t$-tests for differences between pre-and post-test data and differences between gain scores for trained and untrained school counsellors

\begin{tabular}{|c|c|c|c|c|c|c|c|}
\hline \multirow[b]{2}{*}{$\begin{array}{l}\text { Scale for Coaching } \\
\text { Skills (SCS) }\end{array}$} & \multicolumn{2}{|c|}{$\begin{array}{l}\text { Trained group } \\
\quad(n=18)\end{array}$} & \multicolumn{2}{|c|}{$\begin{array}{l}\text { Untrained group } \\
\qquad(n=8)\end{array}$} & \multicolumn{2}{|c|}{ Pre-post gain } & \multirow[b]{2}{*}{$t$} \\
\hline & Pre & Post & Pre & Post & $\begin{array}{l}\text { Trained } \\
\text { group }\end{array}$ & $\begin{array}{l}\text { Untrained } \\
\text { group }\end{array}$ & \\
\hline SCS total & 3.60 & 3.69 & 3.67 & 3.77 & 0.08 & 0.09 & -0.05 \\
\hline Developing autonomy & 3.11 & $3.53^{\star}$ & 3.56 & 3.60 & 0.42 & 0.04 & 1.26 \\
\hline Feedback & 4.15 & 3.81 & 3.93 & 3.63 & -0.34 & 0.30 & -0.14 \\
\hline Purposefulness & 3.11 & 3.40 & 3.26 & 3.64 & 0.28 & 0.38 & -0.32 \\
\hline Trust building & 4.05 & 4.01 & 3.94 & 4.19 & -0.04 & 0.25 & -0.96 \\
\hline $\begin{array}{l}\text { Perceived effects on } \\
\text { instructional practice }\end{array}$ & 3.14 & 3.26 & 3.33 & 3.30 & 0.11 & -0.04 & 0.58 \\
\hline
\end{tabular}

${ }^{*} p<0.05$.

should be noted that the coached teachers rated the coaching skills of the school counsellors very positively, even at pre-test. All of the scores from the teachers, including those for the effects of coaching on their own instructional practice, were above average.

\section{Discussion}

The results of the present study suggest that the training programme had a positive effect on the coaching skills of school counsellors. The trained school counsellors were generally rated higher by the expert raters on the Scale for Coaching Skills (SCS) than the untrained school counsellors. Significant differences between trained and untrained school counsellors were found for the total SCS and three subscales: 'developing autonomy', 'purposefulness', and 'feedback' (for the post-conference).

The training programme was found to improve the skills of 'developing autonomy' and 'purposefulness' in particular. Developing autonomy (or empowerment) refers to strengthening the autonomy of the teachers in order to enable them to reflect on their instructional effectiveness and formulate action plans for the improvement of their teaching. Purposefulness refers to the willingness of the coach and the teacher to focus on the purpose of the coaching conference: to develop alternatives for the improvement of instructional effectiveness. With regard to 'trust building,' the trained school counsellors showed significant improvement at post-test while the untrained school counsellors also showed improvement at post-test (although not significant). This explains the absence of significant differences between the trained and untrained groups on this subscale. The improvement in trust building skills is presumably a result of greater familiarity with the coach at post-test than at pre-test. 
When the feedback scores were aggregated for pre- and post-conference, no significant differences were found between the pre- and post-test scores for the trained group or the trained and untrained groups. As already noted, however, consideration of the feedback scores for the post-conference alone revealed significant differences. This is an encouraging outcome because the provision of feedback can be regarded as a very important skill for the post-conference. Feedback is provided to discuss the analysis of the observation and to produce a self-plan for instructional improvement. Feedback gives the teachers the opportunity to adjust their performance in terms of 'reflection-on-action' (Schön, 1983). The key characteristics of effective feedback are that it be timely, sufficient, concrete, specific, and limited to a small number of performance problems at a time. The trained school counsellors clearly showed better feedback skills during the post-conference than the untrained school counsellors and better feedback skills at post-test than at pre-test.

Although it was attempted to obtain an experimental group of about 25 school counsellors, this effort was not very successful. Of the school counsellors initially committed to the training, five had to withdraw because of time constraints and two could not find opportunities for the coaching conferences. This reduced the final experimental group to 18 school counsellors. Two of the school counsellors in the control group could not find time for the coaching conferences, which reduced the control group to a total of 10 school counsellors.

Considerable time and effort was invested in the encouragement of the trained school counsellors to conduct the entire coaching sequence at post-test: pre-conference, observation and post-conference. A number of the school counsellors, however, found it difficult to convince the teachers to participate in the three different stages in the coaching process. Coaching was a completely new experience for these teachers, and the long delays in the post-tests confirm our observation that coaching is not a common practice in Dutch schools and thus not well understood.

The high ratings from the coached teachers with respect to the skills of the school counsellors even at pre-test nevertheless show the teachers to experience coaching as something positive. The teachers felt very honoured by the special attention from the school counsellors and expressed this in their ratings. A ceiling effect thus resulted, and it was almost impossible to improve the pre-test scores. The positive ratings from the coached teachers also showed them to perceive the coaching conferences as improving their instruction. The reflection on the instructional practices and framing of self-plans for improvement presumably enhance the possibilities for real changes as well.

In this study, the effects of a training programme directed at the coaching of teachers were examined. The trained school counsellors were found to put a number of important and desirable coaching skills into practice. Whether these coaching skills will bring about changes in the cognitive processes and instructional actions of the teachers and subsequently enhance student learning remains to be considered in future research. 


\section{Acknowledgements}

The research reported here was supported by the Protestant Educational Advisory Centre (Christelijk Pedagogisch Studiecentrum), Hoevelaken, The Netherlands. The author gratefully acknowledges the following persons for their contributions to this study: $H$. de Jonghe (doctoral student), E. van Wezel (doctoral student), K. Vernooy (CPS), C. Compagnie (CPS), Y. Leenders (CPS), L. Bouts (Research Technische Dienstverlening, University of Nijmegen), and the participating school counsellors and teachers.

\section{REFERENCES}

Association for Supervision and Curriculum Development (1988) Another Set of Eyes: conferencing skills (Alexandria, Association for Supervision and Curriculum Development).

BAKER, R.G. (1983) The contribution of coaching to transfer of learning: an extension study, unpublished doctoral dissertation, University of Oregon.

BENNETT, B. (1987) The effectiveness of staff development training practices: a meta-analysis, unpublished doctoral dissertation, University of Oregon.

CoHEN, J. (1960) A coefficient of agreement for nominal scales, Educational and Psychological Measurement, 20, pp. 37-46.

Commissie ToEkomst LeRAARSChaP (1993) Een beroep met perspectief: de toekomst van het leraarschap [A profession with perspective: the future of the teaching profession] (Zoetermeer, Ministerie van Onderwijs en Wetenschappen).

Cogan, M.L. (1973) Clinical Supervision (Boston, MA, Houghton Mifflin).

Costa, A.L. \& Garmston, R.J. (1994) Cognitive coaching: a foundation for Renaissance schools (Norwood, NJ, Christopher-Gordon).

DE JONGHE, H. \& VAN WeZel, E. (1994) Coaching: Een onderzoek naar de effecten van het trainingsprogramma 'De schoolbegeleider als coach' [Coaching: a study examining the effects of the training program, The school counsellor as coach], Masters thesis, University of Nijmegen.

GoldHAmmer, R. (1969) Clinical Supervision: special methods for the supervision of teachers (New York, Holt, Rinehart \& Winston).

GoldHAMMER, R., ANDERSON, R.H. \& KRAJEWSKI, R.J. (1980) Clinical Supervision: special methods for the supervision of teachers, 2nd edn (New York, Holt, Rinehart \& Winston).

GoldhAMmer, R., ANDERSON, R.H. \& KRAJEwSK, R.J. (1993) Clinical Supervision: special methods for the supervision of teachers, 3rd edn (New York, Holt, Rinehart \& Winston).

HoutveEN, A.A.M. (1990) Begeleiden van vernieuwingen (Guidance of change), doctoral dissertation, University of Utrecht.

HUNTER, L. (1986) Let's eliminate the preobservation conference, Educational Leadership, 43, pp. $69-70$.

Hunter, M. \& Russell, D. (1990) Mastering Coaching and Supervision (El Segundo, TIP Publications).

JOYCE, B. \& SHOWERS, B. (1980) Improving inservice training: the messages of research, Educational Leadership, 37, pp. 379-385.

JoYce, B. \& SHOWERS, B. (1982) The coaching of teaching, Educational Leadership, 40, pp. 4-8. Joyce, B. \& SHOwers, B. (1988) Student Achievement through Staff Development (New York, Longman).

KINLAW, D.C. (1989) Coaching for Commitment: managerial strategies for obtaining superior performance (San Diego, CA, University Associates).

Nolan, J., Hawkes, B. \& Francis, P. (1993) Case studies: windows onto clinical supervision, Educational Leadership 51, pp. 52-56. 
PaJak, E. (1993) Approaches to Clinical Supervision: alternatives for improving instruction (Norwood, NJ, Christopher-Gordon).

Pavan, B.N. (1985) Clinical supervision: research in schools utilizing comparative measures, paper presented at the Annual Meeting of the American Educational Research Association, Chicago (ERIC Document Reproduction Service No. ED 255 516).

Pavan, B.N. (1991) Determining the usages of clinical supervision, paper presented at the Annual Meeting of the American Educational Research Association, Chicago (ERIC Document Reproduction Service No. ED 336 374).

PAVAN, B.N. (1993) Examining clinical supervision practice, in: R.H. ANDERSON \& K.J. SNYDER (Eds) Clinical Supervision: coaching for higher performance, pp. 135-154 (Lancaster, Technomic).

RoELOFS, E. (1993) Teamgerichte nascholing en coaching: Een experimentele studie in scholen met combinatieklassen [Staff development and coaching: an experimental study in schools with multi-grade classes], doctoral dissertation, University of Nijmegen).

RoElofs, E., VEENMAN, S. \& RAEMAEKERS, J. (1994) Improving instruction and classroom management behaviour in mixed-age classrooms: results of two improvement studies, Educational Studies, 20, pp. 105-126.

ScHÖN, D.A. (1983) The Reflective Practitioner (New York, Basic Books).

SERGIOVANNI, T.J. \& STARRATT, R.J. (1983) Supervision: human perspectives (New York, McGraw Hill).

SHOWERS, B. (1982) Transfer of Training: the contribution of coaching (Eugene, OR, University of Oregon, Center for Educational Policy and Management) (ERIC Document Reproduction Service No. ED 231 035).

SPARKS, G.M. \& BRUDER, S. (1987) How school-based peer coaching improves collegiality and experimentation, paper presented at the Annual Meeting of the American Educational Research Association, Washington.

VeEnman, S., DE Jonghe, H. \& VAN WeZEL, E. (1995) De schoolbegeleider als coach: een werkboek voor de begeleidingspraktijk [The school counsellor as coach: training manual] (Hoevelaken, Christelijk Pedagogisch Studiecentrum).

Veenman, S., LeM, P. \& RoElofS, E. (1989) Training teachers in mixed-age classrooms: effects of a staff development programme, Educational Studies, 15, pp. 165-180.

VEENMAN, S. \& RAEMAEKERS, J. (1995) Long-term effects of a staff development programme on effective instruction and classroom management for teachers in multi-grade classrooms, Educational Studies, 21, pp. 167-185. 